\title{
Multi-Dimensional Success Factors of Agile Software Development Projects
}

\author{
Nagy Ramadan Darwish \\ Department of Computers and Information Sciences \\ Institute of Statistical Studies and Research \\ Cairo University \\ Cairo, Egypt
}

\author{
Nancy M. Rizk \\ Arab Academy for Science Technology \& Maritime \\ Transport \\ Cairo, Egypt
}

\begin{abstract}
This paper focuses on providing a multi-dimensional view of success factors in agile software development projects. This paper starts by surveying the literature for the success factors of agile software development projects. Therefore, it surveys the success factors that were published in research papers, articles, and technical reports related to actual agile projects. For facilitating the understanding of the success factors, the researchers classify them into five categories: organizational, people, process, project, and technical. In addition, the researchers classify the success factors into main success factors where each main success factor is decomposed into a set of sub success factors. This classification helps in reaching to a multi-dimensional view of success factors and makes them more applicable. Then, the researchers propose an approach for evaluating the adherence of these success factors in the agile projects. The proposed approach can be used to reveal the current state of the success factors as an introductory step to enhance their adherence.
\end{abstract}

\section{Keywords}

Success Factors, Agile Methods, Agile Projects, Software Development projects.

\section{INTRODUCTION \& BACKGROUND}

Software is a necessity and used in many industries and organizations with different disciplines. However the number of successful software projects is few comparing to the total number of software development projects. Figure 1 illustrates the percentage of successful, challenged and failed software projects from year 2004 to year 2012 resulted from CHAOS manifesto [1].

\begin{tabular}{|l|c|c|c|c|c|}
\hline & $\mathbf{2 0 0 4}$ & $\mathbf{2 0 0 6}$ & $\mathbf{2 0 0 8}$ & $\mathbf{2 0 1 0}$ & $\mathbf{2 0 1 2}$ \\
\hline Successful & $29 \%$ & $35 \%$ & $32 \%$ & $37 \%$ & $39 \%$ \\
\hline Failed & $18 \%$ & $19 \%$ & $24 \%$ & $21 \%$ & $18 \%$ \\
\hline Challenged & $53 \%$ & $46 \%$ & $44 \%$ & $42 \%$ & $43 \%$ \\
\hline
\end{tabular}

Fig 1: Project resolution results from CHAOS research from years 2004 to 2012

From the figure, we find that around $60 \%$ of the projects were challenged or failed through years 2004 to 2012 and this considered as high percentage of failure. Therefore, many researches proposed many substitutes and efforts in software development process. A booming trend in software development is the agile methodology. It provides more flexibility in software development process such as quick delivery, simple phases, concerning on changes of requirements and also strong communication between developers and customers. All these factors are strongly contributes to a successful software development process [2]. The word agile means the ability to move easily and quickly [3]. An adaptive agile method in software development indicates that agile method provides the flexibility to adapt to changes over time. The key intent of agile solution delivery is to provide value to an organization in increments, which are adjusted and built over time into a scalable solution [4]. Agile was introduced to overcome the problem of waterfall methodology in early 90's. Agile is an iterative approach to software development using shorter and lightweight development cycles and some different deliverables [2]. Highsmith,2010 described agile methods, that its formula of success is deliver today, and adapt tomorrow[5]. Agile software development manifesto was developed by the agile alliance group, to state for: [6] We are uncovering better ways of developing software by doing it and helping others do it. Through this work we have come to value:

"Individuals and interactions over processes and tools Working software over comprehensive documentation Customer collaboration over contract negotiation

Responding to change over following a plan

That is, while there is value in the items on the right, We value the items on the left more."

Agile methods are based on 12 main principals as defined by the agile manifesto [7]. The life cycle phases in agile software development start with project initiation which is creating the project team, plan the requirements and resources needed. Second phase is to release the deliverable by iteration process in time box form. Each time box consists of plan, developed and reviewed process. It will have specific time to be deliverable. This iteration process will take place until all the requirements are coped and agreed by both customers and the project team. Then, the project is closed [2].

Agile software development processes include Scrum, Extreme Programming (XP), Open Unified Process (OpenUP), agile instantiations of Rational Unified Process (RUP), and Agile Modeling (AM) [8]. There are many more methods than the previous ones but those are the most common in agile methods[9]. Agile methods provide more advantages than traditional methods; agile methods break tasks into small increments with minimal planning, they involve efficient and face to face communication with 
customers making the customer an active point in the development process. "Stand ups" are a brief session where team members report to each other what they did the previous day, what they intend to do today, and what their roadblocks are, and finally specific tools and techniques are often used to improve quality and enhance project agility [10].

However not only choosing the suitable agile method is the key success factor in software development but there are many success factors that contribute to the agile methods in order to raise the percentage of success of the software.

The Critical Success Factor (CSF) approach for identifying and measuring an organization's performance was first developed by Rockhart (1979) and later on refined and became well- established [10]. CSF is defined by Bullen and Rockhart (1981) as "the limited number of areas in which satisfactory results will ensure successful competitive performance for the individual, department or organization. CSF's are the few key areas where 'things must go right' for the business to flourish and for the managers goal to be attained" [11]. That was a definition for the critical success factors in general but in this paper we will study the success factors for agile software development projects.

In this paper we are going to survey the literature for the success factors of agile methods in software development, classify them into dimensions then into main success factors and sub success factors to reach a narrowed number of success factors to be more understandable and applicable. This process is illustrated in figure 2 . In order to evaluate the adherence of these success factors in the agile project we proposed an evaluation approach that conducted a questionnaire and the methodology of analyzing this questionnaire, also an algorithm was written and a flow chart was drawn to explain the proposed approach.

The rest of the paper is organized as follows: section 2 covers related work, section 3 covers the surveyed success factors, section 4 covers the proposed success factors framework, section 5 covers the proposed evaluation approach, section 6 covers the conclusion and future work, and finally the references can be found in section 7 .

\section{RELATED WORK}

There are many related work found in literature and we can classify them according to the research methodology performed. One based on case study or questionnaire analysis, two based on literature survey, and third based on comparative study with another research.

- For the comparative based study we surveyed only one paper. [12] The paper presented a literature survey of critical success factors that impact software projects. Forty-three articles from the years 1990 to 2010 were analyzed to develop a list of critical factors that specifically affect the success of software projects. The method of content analysis and frequency analysis was adopted. Twenty-six critical success factors were found to be related to software project success. The study suggested that organization or project manager is attentive to control the top five critical factors to drive towards project success since the percentage of frequency of occurrences for each is more than $50 \%$. It found that the factors of clear and frozen requirements, realistic estimation of the schedule and budget, and a competent project manager are the five most critical success factors of software projects.

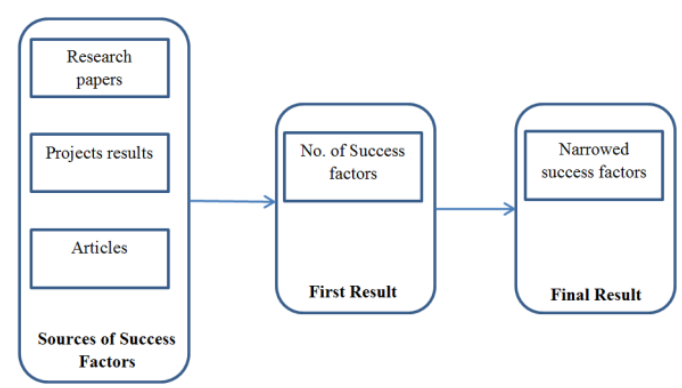

Fig 2: process of narrowing down the success factors

- For the literature based study we surveyed two papers, one book and two IEEE articles. The book [13] mentioned the key success factors for agile methods software development, it mentioned that most critical success factors depend on the point of view of the project manager so it advised the project managers to pick the success factors that will bring more return on investment and implement them. The article [14] was talking about the failure factors of the agile software and we get the opposite as success factors. The other article [15] was talking specifically about the people factors in software development and how this factor can lead to the success of the project. The papers [2] and [16] surveyed the literature for the critical success factors in agile methods and mentioned them. Only paper [16] classified the factors under three categories; technical, organizational, and people; and developed a framework for these factors.

- For the case study based we surveyed seven papers. Paper [17] presented an investigative study of the main factors that affect IT projects success in Saudi Arabian public organizations. A two-phase approach has been adopted combining qualitative and quantitative research methods. Phase 1, performed a qualitative approach using semistructured interview method was used to collect and analyze the data, and the findings of this phase proposed seventeen factors. Then, in phase 2, a quantitative approach using questionnaire method was used to assess and validate the outcomes of phase I. The results of the questionnaire confirmed the importance of those seventeen factors, and the critical success factors of IT projects in Saudi Arabian public organizations to be found are: project management, project team competency, communication management, top management support and commitment, strategic planning, training and education, partners and suppliers management, and stakeholders management.

- Paper [18] used views of skilled and experienced project managers to explore the contribution of success factors and management approach to project success. This study used a sample of 519 project managers with experience leading or working on IT projects and employed a two phased research approach by employing a frequency analysis of project manager preferences for the entire sample followed by a $\mathrm{Q}$ analysis to evaluate and group a set 
of critical success factors and provided an explanation for those critical success factors.

- Paper [19] investigated two agile software development teams in an open source organization based on an explorative research design. The focus was on the empirical identification of success and failure in the application of agile methods in teams with open source background, structure and characteristics and in comparison with the literature findings. The findings are currently induced from the interview data. They included four success and two failure factors.

- Paper [25] applied the twelve agile development principles, and adaptive project management life cycle model to case study of $\mathbf{J}$ group, it identified the critical success factors of running Scrum as follows: 1) building learning organization and a self-managing group with Scrum; 2) professional agile development and release capability; 3 ) explicit the process of project management. $J$ group as a pioneer Scrum agile software development practices, realizes the productivity of significant promotion and cost reduction, accelerates the product to the market, improves customer satisfaction and achieves a more transparent development process and higher predictive capability. The study aims to improve the success rate of the running Scrum.

- Paper [20] A five-round Delphi study was conducted to determine the degree to which the Team Software Process (TSP) can address the identified critical success factors for software projects. Three high-reputation and high-caliber experts participated in this study. Our results found agreement among the experts that the TSP provided the 'Best Practices' for addressing 14 critical success factors. The experts also agreed that the TSP provided a 'Very Good' framework for addressing 4 critical success factors. Our findings further suggested that 6 critical success factors were addressed by the TSP at a 'Good' level; only 1 critical success factor was addressed to a limited degree and none of the critical success factors were addressed at the 'Fair' level.

- Paper [21] aimed to identify and assess the critical success factors for projects in Ghana, The study is an exploratory approach, utilized a survey method to collect data on project management practices of Ghanaian organizations. Results of the study indicated that the critical factors that contribute to the questionnaire and applied knowledge creation theory to analyze the open source software community to find the critical success factors of agile software projects improvements.

- Finally paper [10] performed quantitative survey among Agile professionals, gathering survey data from 109 Agile projects from 25 countries across the world. Multiple regression techniques were used, both at the full regression model and at the optimized regression model via the stepwise screening procedure. The results showed that only 10 out of 48 hypotheses were supported.

\section{SUCCESS FACTORS}

The Critical Success Factor (CSF) approach for identifying and measuring an organization's performance was first developed by Rockhart (1979) and later on refined and became well- established [10] . CSF is defined by Bullen and Rockhart (1981) as "the limited number of areas in which satisfactory results will ensure successful competitive performance for the individual, department, or organization. CSF's are the few key areas where 'things must go right' for the business to flourish and for the managers goal to be attained" [11].

That was a definition for the critical success factors in general but in this paper we will study the success factors for agile software development projects. We will survey the literature for critical success factors or success factors and list them all. Many researches in the literature classify the success factors into categories concerning technicalities, project, people, organization...etc. The categories are not the same in every research, so we preferred not to classify the success factors. The collected success factors are summarized in table1.

Table 1. Success factors for agile projects

\begin{tabular}{|c|c|c|}
\hline$\#$ & Success factor & Publication \\
\hline 1 & $\begin{array}{l}\text { Clear requirements and } \\
\text { specifications }\end{array}$ & {$[22],[16],[15],[20],[13]$} \\
\hline 2 & Clear objectives and goals & $\begin{array}{l}{[22],[12],[14],[16],[20],[1} \\
3],[24],[1]\end{array}$ \\
\hline 3 & Realistic schedule & $\begin{array}{l}{[22],[12],[20],[13],[24],[1} \\
]\end{array}$ \\
\hline 4 & $\begin{array}{l}\text { Support from top } \\
\text { management }\end{array}$ & $\begin{array}{l}{[2],[14],[20],[13],[17],[24} \\
],[1]\end{array}$ \\
\hline 5 & $\begin{array}{l}\text { Effective project } \\
\text { management skills }\end{array}$ & {$[22],[13],[17],[23],[24]$} \\
\hline 6 & User involvement & $\begin{array}{l}{[22],[13],[2],[12],[15],[12} \\
],[20],[13],[17],[24],[1]\end{array}$ \\
\hline 7 & $\begin{array}{l}\text { Effective communication } \\
\text { and feedback }\end{array}$ & $\begin{array}{l}{[22],[2],[13],[16],[13],[17} \\
],[23],[24]\end{array}$ \\
\hline 8 & Corporate culture & {$[2],[12],[14],[15]$} \\
\hline 9 & Simplicity in process & {$[2],[22],[13]$} \\
\hline 10 & Time allocation & {$[2],[12]$} \\
\hline 11 & Team size & {$[2],[21]$} \\
\hline 12 & Active testing & {$[2],[15]$} \\
\hline 13 & Code review & {$[2]$} \\
\hline 14 & Team Environment & {$[12],[21]$} \\
\hline 15 & Team Capability & $\begin{array}{l}{[12],[22],[14],[15],[21],[2} \\
0],[13],[17],[23],[24]\end{array}$ \\
\hline 16 & $\begin{array}{l}\text { Project Management } \\
\text { Process }\end{array}$ & $\begin{array}{l}12],[22],[16],[20],[13],[1 \\
7],[1]\end{array}$ \\
\hline 17 & Project Definition Process & {$[12]$} \\
\hline 18 & Delivery Strategy & {$[12]$} \\
\hline 19 & Project Nature & {$[12]$} \\
\hline 20 & Project Type & {$[12]$} \\
\hline 21 & Realistic budget & {$[22],[20],[13],[24],[1]$} \\
\hline 22 & $\begin{array}{l}\text { Familiarity with } \\
\text { Technology }\end{array}$ & {$[22],[13],[17]$} \\
\hline 23 & $\begin{array}{l}\text { Minimum change in } \\
\text { requirements }\end{array}$ & {$[22],[2],[13]$} \\
\hline 24 & Risk management & {$[22],[16],[13],[17],[24]$} \\
\hline 25 & Configuring the necessary & [14].[1] \\
\hline
\end{tabular}




\begin{tabular}{|l|l|l|}
\hline & tools and infrastructure & \\
\hline 26 & $\begin{array}{l}\text { Using advanced } \\
\text { technology }\end{array}$ & {$[14],[16],[17],[24]$} \\
\hline 27 & $\begin{array}{l}\text { Selecting proper agile } \\
\text { method }\end{array}$ & {$[13],[12],[24] .[1]$} \\
\hline 28 & $\begin{array}{l}\text { Accurate estimates of } \\
\text { project resources }\end{array}$ & {$[16],[24],[1]$} \\
\hline 29 & $\begin{array}{l}\text { Good reporting of project } \\
\text { status }\end{array}$ & {$[16]$} \\
\hline 30 & $\begin{array}{l}\text { Ability to handle the } \\
\text { project's complexity }\end{array}$ & {$[16]$} \\
\hline 31 & Stakeholder politics & {$[16],[24]$} \\
\hline 32 & Commercial pressures & {$[16]$} \\
\hline 33 & Team distribution & {$[15]$} \\
\hline 34 & Decision time & {$[15]$} \\
\hline
\end{tabular}

\section{PROPOSED SUCCESS FACTORS FRAMEWORK}

After surveying the literature for the success factors in agile methods or software development we will come up with our proposed success factor framework depicted in Table 2 . The proposed success factors framework classifies the collected success factors into 5 dimensions; organizational, process, project, people and technical. Under each classification we have main success factor and sub factor(s). We may have main success factor with no sub factors because we didn't find suitable sub success factors from the literature. We have to note here that the classification and the division of main and sub factors are from the authors point of view.

\section{A.Organizational factors}

The Organization has a great effect on the success of the project. The culture can influence many things in the agile software development. We can see from the framework in figure 1, that corporate culture includes support from top management in the agile software development process, it can affect how the user is involved into the software development process and finally it determines the environment where the team of the software development operates.

- Corporate culture

- $\quad$ Support from top management

- User involvement

- Team Environment

\section{B.Technical factors}

Technical factors are factors that have an impact on how a project operates and are related to the software, technology or hardware used within the project development process [18]. We mentioned two main factors which are selecting proper agile method according to the project conditions and constraints, and usage of advanced technology in the project

- $\quad$ Selecting proper agile method

- Configuring the necessary tools and infrastructure
- Using advanced technology

- Familiarity with Technology

\section{People factors}

The success of a software development project is often related to people factors. Human resources factors are also hypothesized as important factors for the success of agile software development projects [12].

Under this dimension we have the user involvement and team capability main factors and below each one of them we have other sub factors, e.g. under the team capability there are the effective skills required to manage the project, the ability of the team, project manager to handle the project's complexity, perfectly manage the decision time required, and effective communication and feedback with the user or within the team for each task required.

- User involvement

- Handling commercial pressures

- Stakeholder politics

- Team Capability

- Effective project management skills

- Ability to handle the project's complexity

- Decision time

- Effective communication and feedback

\section{Process factors}

Process factors are those related to the tasks process or functions of the project itself e.g. testing and reviewing the code of the software, reporting of the project status , and risk management. Below is our main and sub factors classification of the process success factors.

- $\quad$ Project Management Process

- Minimum change in requirements

- Simplicity in process

- $\quad$ Good reporting of project status

- $\quad$ Project Definition Process

- $\quad$ Risk management

- Time allocation

- Accurate estimates of project resources

- $\quad$ Active testing

\section{- $\quad$ Code review}

\section{E. Project factors}

Project factors are those concerned with the project of agile software development from setting clear objectives and goals, determining project type and nature, setting the project schedule, estimating realistic budget, and specifying clear requirements and specifications. 
Table 2. Proposed framework for success factors of agile projects

\begin{tabular}{|c|c|c|}
\hline Dimension & Main Success Factors & Sub Success Factors \\
\hline \multirow[t]{2}{*}{ Organizational } & \multirow{2}{*}{ Corporate Culture } & Support from top management \\
\hline & & Team Environment \\
\hline \multirow[t]{6}{*}{ People } & \multirow{2}{*}{ User involvement } & Handling commercial pressures \\
\hline & & Stakeholder politics \\
\hline & \multirow{4}{*}{ Team Capability } & Effective project management skills \\
\hline & & Ability to handle the project's complexity \\
\hline & & Decision time \\
\hline & & Effective communication and feedback \\
\hline \multirow[t]{7}{*}{ Process } & \multirow{3}{*}{ Project management process } & Minimum change in requirmeents \\
\hline & & Simplicity in process \\
\hline & & Good reporting of project status \\
\hline & \multirow{3}{*}{ Project definition process } & Risk management \\
\hline & & Time allocation \\
\hline & & Accurate estimates of project resources \\
\hline & Active testing & Code review \\
\hline \multirow[t]{6}{*}{ Project } & \multirow{2}{*}{ Clear objectives and goals } & Project type \\
\hline & & Project nature \\
\hline & Realistic schedule & \\
\hline & \multirow{2}{*}{ Realistic budget } & Team distribution \\
\hline & & Team size \\
\hline & Clear requirements and specifications & \\
\hline \multirow[t]{2}{*}{ Technical } & Selecting proper agile method & Configuring the necessary tools and infrastructure \\
\hline & Using advanced technology & Familiarity with technology \\
\hline
\end{tabular}

- Clear objectives and goals

- $\quad$ Project Type

- Project Nature

- Realistic schedule

- Realistic budget

- Team distribution

- Team size

- Clear requirements and specifications

\section{PROPOSED EVALUATION APPROACH}

In this section we are going to propose an approach for evaluating the adherence of the success factors in agile projects. We are going to propose an adapted questionnaire then describe the data analysis should be used to get results of the questionnaire that evaluate the adherence and existence of the success factors in agile projects. The data analysis of the questionnaire includes analysis of one success factor, or all success factors. An algorithm and a flow chart were provided for implementing the proposed approach and evaluating the success factors in an agile project.

\section{A. Questionnaire Structure}

A survey method should be used to gather data. The target population should be agile approach projects.
The questionnaire is inspired and adapted from [10] and [17]. There are three sections in the questionnaire:

- $\quad$ SECTION A on the project demographic data, and agile project information. This section sought data on the age or longevity of existence of the organizations, form of organization, nature of ownership, organizational structure, respondents' function, name of the project, size of the project in terms of time, budget and number of team members, staff strength, and agile method used. Estimated number of questions in this section is 10 questions.

- $\quad$ SECTION B on success factors existence in the project environment. In this part we have five dimensions of the success factors (organization, people, process, project and technical) and under each dimension we have the main success factors and their sub factors. A 5-point Likert scale is used to reflect the level of existence of the sub factors and the main factors. Estimated number of questions in this section is 33 questions (note: we would consider the main factor to be an independent question for the sake of double checking the answers of the respondent).

- SECTION C for additional comments, where respondents are invited to enter any feedback or thought on a free text area.

A proposed form of the questionnaire is going to be like figure 3 . 


\begin{tabular}{|c|c|c|c|c|c|}
\hline \multicolumn{6}{|l|}{ Section A: Company data and project information } \\
\hline \multicolumn{6}{|l|}{ Q1: } \\
\hline \multicolumn{6}{|l|}{ Q2: } \\
\hline \multicolumn{6}{|l|}{ Q.. } \\
\hline \multicolumn{6}{|l|}{ Section B: Success Factors } \\
\hline \multicolumn{6}{|l|}{ Dimension a (Organization) } \\
\hline Choose the correct existence level & Very Poor & Poor & Not Exists & Good & Very Good \\
\hline \multicolumn{6}{|l|}{ (Main Success factor) Corporate Culture } \\
\hline \multicolumn{6}{|l|}{ Sub factor1: Support from top management } \\
\hline \multicolumn{6}{|l|}{ Sub factor2: Team environment } \\
\hline \multicolumn{6}{|l|}{ Section C: } \\
\hline Additional Comments or Feedback & & & & & \\
\hline
\end{tabular}

Fig 3: Proposed Questionnaire form

\section{B. Data analysis}

After distributing the questionnaire over the organizations that adopt agile methods projects and collecting the data, data analysis should be applied in order to get the results of the degree in which each success factor exists in each project under survey.

To calculate the degree of existence of one factor we calculate the summation of corresponding value of each sub-factor and then obtain the results as follows

- $\quad$ Zero $-\left(1^{*}\right.$ no of sub-factors $)$ the result is very poor,

- $\quad(1 *$ no of sub-factors $)-(2 *$ no of subfactors) the result is poor

- $\quad(2 *$ no of sub-factors $)-(3 *$ no of subfactors) the result is good

- $\quad(3 *$ no of sub-factors $)$ - $(4 *$ no of subfactors) the result is very good

To calculate the degree to which all success factors exist in the project, we calculate the summation of the corresponding values for all of the success factors and then obtain the results as follows:

Zero $-(1 *$ no of success factors $)$ the result is very poor,

- $\quad(1 *$ no of success factors $)-(2 *$ no of success factors) the result is poor

- $\quad(2 *$ no of success factors) - (3* no of success factors) the result is good ( $3 *$ no of success factors) - $(4 *$ no of success factors) the result is very good

To get the average existence of the success factors in the project we calculate the summation of the corresponding values for all of the success factors and divide it over the number of questions in
section-B and also obtain the results as the previous part.

\section{Algorithm and flow chart for applying the proposed} approach

The proposed approach for the evaluation of the adherence of success factors in agile project is being depicted using an algorithm as in figure 4 and the flow chart in figure 5. The algorithm and flow chart demonstrate mainly the data analysis of the questionnaire including analysis of one success factor, or all success factors. An algorithm and a flow chart were provided for implementing the proposed approach and evaluating the success factors in an agile project.

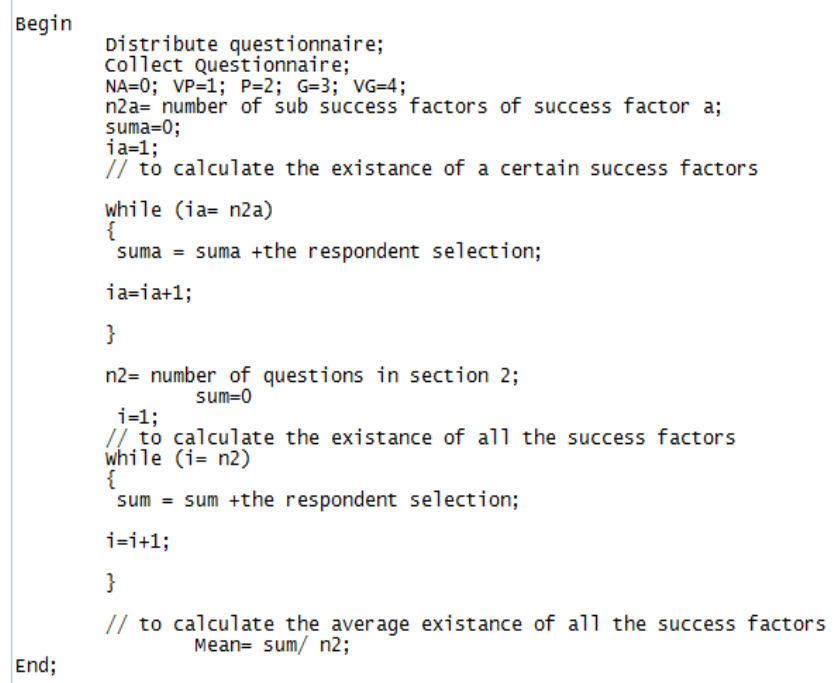

Fig 4: Algorithm of the proposed evaluation approach 


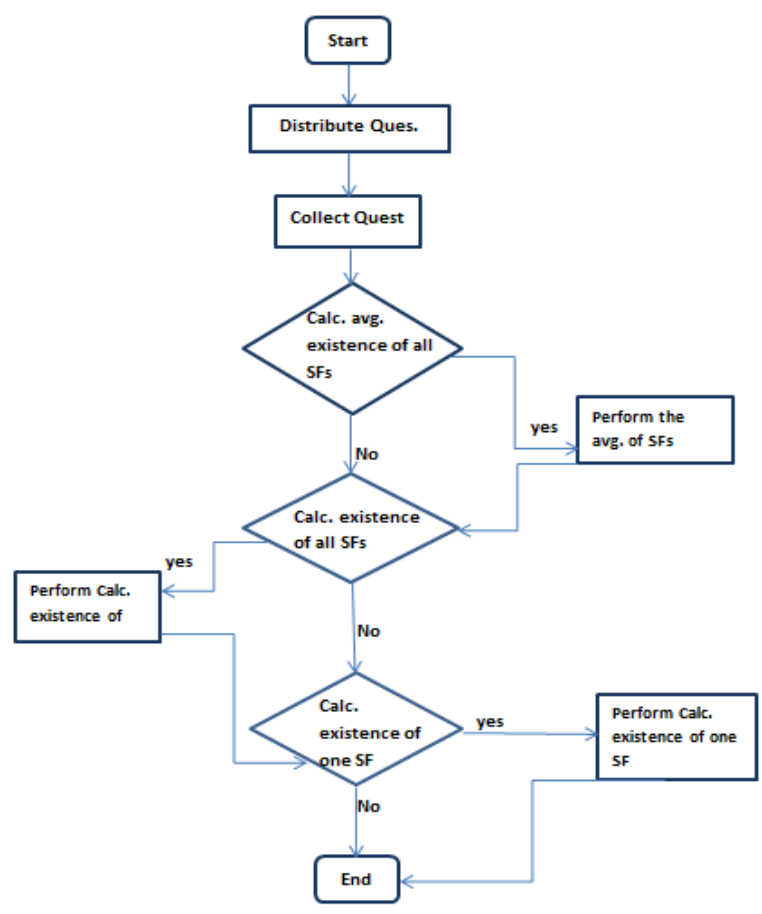

Fig 5: Flow chart for the proposed evaluation approach

\section{CONCLUSION \& FUTURE WORK}

In this paper we attempted to review the important factors for the success of agile software development projects. We have presented a conceptual framework illustrating five dimensions of success factors of agile projects ,the main success factors and the sub success factors under each dimension to reach for a narrowed number of success factors for more understandability and applicability. And finally proposed an approach for evaluating the adherence of the success factors in an agile project providing data analysis method, and the algorithm and flow chart for performing or implementing the approach. Since we only provided a theoretical approach so we need to practically implement it on many agile software development projects in the future, and also some statistical studies can be performed to minimize the number of success factors to reach for the critical success factors.

\section{REFERENCES}

[1] CHAOS manifesto 2013, Standish Group International.

[2] Mansor, Z., Yahya, S., Habibah, N., Success determinants in agile software methodology, web resources https://www.academia.edu/662661/Success_Determinant s_in_Agile_Software_Development_Methodology. Accessed [30/11/2014]

[3] Full Definition of AGILE: http://www.merriamwebster.com/dictionary/agile [accessed 21-1-2015]

[4] Gorans, P., Kruchten, P., 2014, A guide to critical success factors in agile delivery, IBM center for the business of government

[5] Highsmith, J., 2010, Agile project management: creating innovative products.

[6] Manifesto for Agile Software Development: www.agilemanifesto.org. Accessed [30/11/2014]
[7] Principles behind the Agile Manifesto: http://agilemanifesto.org/principles.html. Accessed [30/11/2014]

[8] Ambler, S., 2010, Scaling agile: an executive guide, IBM agility at scale.

[9] Larman, C., 2004, Agile and Iterative Development: A Manager's Guide. Addison-Wesley. p. 27. Wikipedia agile software development.

[10] Chow, T., Cao, D., 1981, A survey study on critical success factors of agile software, Journal of Systems and Software, Volume 81, Issue 6, Pages 961-971

[11] Bullen, C.V., Rokhart, J.F.,A, 1981, primer on critical success factors, working paper no.69, Massachusetts institute of technology, Sloan School of management, center of information systems research, Cambridge, Massachusetts.

[12] Nasir, M. H. N. and Sahibuddin, S., 2011, Critical success factors for software projects: a comparative study. Scientific Research and Essays, 6 (10). pp. 2174 2186.

[13] Wan, J. and Wang, R., 2010, Empirical Research on Critical Success Factors of Agile Software Process Improvement, Journal of Software Engineering and Applications, Vol. 3 No. 12, pp. 1131-1140.

[14] Charette, R., 2005, Why Software Fails. IEEE Spectrum., 42(9): 42-49.

[15] Cockburn, A., Highsmith, J. 2001, Agile Software Development: The People Factor, Issue No.11 November (2001 vol.34), pp: 131-133, Published by the IEEE Computer Society.

[16] Misra, S. C., Kumar, V., and Kumar, U., 2006, Success Factors of Agile Software Development, International Conference on Software Engineering Research and 
Practice (SERP'06), June, pp. 26-29, 2006, Las Vegas, USA.

[17] Abdulaziz I. A. and Mayhew, P., 2013, An Investigation of the Critical Success Factors of IT Projects in Saudi Arabian Public Organizations, IBIMA Publishing.

[18] Doherty, M. 2012, Examining Project Manager Insights of Agile and Traditional Success Factors for Information Technology Projects: A Q-Methodology Study, PhD, Marian University, Doctoral Dissertation.

[19] Tsirakidis, P., F Kobler, F., Krcmar, H., 2009, Identification of success and failure factors of two agile software development teams in an open source organization, Global Software Engineering, ICGSE 2009. Fourth IEEE International Conference on, pp 295 296.

[20] Nasir, M., Sahibuddin, S., 2011, Addressing a critical success factor for software projects: A multi-round
Delphi study of TSP, International Journal of the Physical Sciences Vol. 6(5), pp. 1213-1232.

[21] Ofori, D., Project Management Practices and Critical Success Factors-A Developing Country Perspective, 2013 International Journal of Business \& Management.

[22] Crispin, L., Gregory, J., 2013, agile testing, Pearson education.

[23] Technological factors definition, Web resource: http://www.businessdictionary.com/definition/technologi cal-factors.html [accessed 12/12/2014]

[24] Fortune, J., White, D., 2013, International Journal of Project Management 24 pp 53-65.

[25] Wan, J., Zhu, Y., Zeng, M., 2013, Case Study on Critical Success Factors of Running Scrum, Journal of Software Engineering and Applications. 